\title{
GRAPHIC LINE AS COMPOSER OF FORMS IN INTERIOR AND EXTERIOR DESIGN
}

\author{
Vaska Sandeva, Katerina Despot \\ Goce Delcev University of Stip, R. Macedonia \\ Krste Misirkov b.b. P.O. Box 201 Stip 2000, Macedonia, \\ e-mail: katerina.despot@ugd.edu.mk, vaska.sandeva@ugd.edu.mk
}

\begin{abstract}
The line is an essential tool in fine and applied arts. The definition saying that the line is a continuous movement of a point in space at one, two or three dimensions (length, height and width) or that the line is connected in two distant points. However, there is also a view that the line is an abstract concept, because it as such does not exist. Its application in interior and exterior transformation and change the line of art in design and after its functional application. Application of old graphics technique in modern spaces. No boundary line between what is art and what is not applied arts in interior design and exterior design. It all starts on the skill of the designer in the creation of good composition and then must create the structure.
\end{abstract}

Keywords: line, graphics, composition, interior, exterior.

\section{INTRODUCTION}

Line form for its distribution and intensity creates certain spatial characteristics. There are two important principles that prove that the line is the adjustable visual factor in the volume of space.

1. All open lines inclination rights.

2. All loops tend to round.

It follows that there is open and closed forms of space and, therefore, once again, that open shapes belonging to two-dimensional space for the closed forms of three-dimensional space. The meaning of certain visual information received line up of underline, i.e. when a stream or meeting with other lines creates a loop of some sort. Dense placement of the line next to one another or above one another creating repair area whose density is to transparent film to the end of the linear structure. It now opens the way to the idea of making the surface table.

In contemporary art this problem is well known. Numerous lines of the same size to that extent smother their material traces and create a layer with a palpable energy put into these movements. This creates a new problem.

The effect of multiple lines on the surface although obviously created layer and introduced energy created and energized zone - tensions that produced the effect of linear organization afloat.

This brings us to the idea that its line of action can achieve for itself an element that does not analyse anything except very existence. With these theses about the ability of the line come in two basic types of expression of the line can persist in some segments of art.

The first types are linear flow to the space as the line "wrapped" around a space as an offer volume. Here is dominant curvilinear move. The second type occurs when introduced energy matter (which leaves traces) is identified with the straight and speed implementation of such a linear structure. We call this creative gesture.

The definition saying that the line is a continuous movement of a point in space at one, two or three dimensions (length, height and width), or that the line is connected in two distant 


\section{ARTTIE Y}

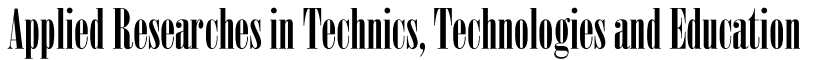

Journal of the Faculty of Technics and Technologies, Trakia University https://sites.google.com/a/trakia-uni.bg/artte/

points. However, there is also a view that the line is an abstract concept, because it as such does not exist. What is called line, although the length has known even minimum height and is actually just very elongated area.

In further exposure line we will treat it as an independent artistic element used in graphics and all his subtlety, as portrayed by printing paint because as such it has specificity in art and in practice.

To be clear, we will disregard, i.e. they will stand out from the picture, with which it is associated most often because the drawing are other artistic elements. In isolated line easily discern its essential characteristics.

\section{TYPES OF LINES AND THEIR FUNCTION}

It is wrong to believe that there are a number of different lines. In fact there are only two types of lines: straight and curved. Other types of lines no. But these two lines make the contents of all graphics are distinguished by energy and tenderness of the author, as it is presented.

The straight line is one. It is always just right, no matter how long, wide, whether vertical or horizontal, dark or light coloured, smooth or rough, if only drawn or deduced with any material. It is constantly moving in the same direction and does not change the angle.

Together with the line moving and the eye and attention of the viewer, it just pulls behind. As is longer, the more uninteresting, in featureless and monotonous. This is due to the repetition of the point without changes in direction, i.e., sole rhythm.

Curve. Unlike rights curved line has a lot of options. They may be very little to very strongly curved, i.e. have very small to very large bending angle. By switching angles can create multiple variations of curved lines that do not really have anything else, but only segments of circles of various sizes.

The chart is used much more straight line from simple reason that it is higher in nature, but also because it provides an opportunity to express different and complex content and messages. In the aesthetics of the past, it was thought that the straight line does not express anything, looking like a secondary line and avoided where not needed, but in modern life is much represented the straight line as an expression of coldness rigor emotional impact.

The line performed aesthetic and practical function. It very easy and quick way to describe, register or define a character or object; to announce thought, intention or information; marked and maintained an idea or a vision; to suggest movement or direction of movement; to express the structure of the object or creature to design or decorate objects and premises; to express different feelings, characters, and many other topics in the field of art.

The lines carry a certain content that shows the viewer.

For example, a clean, sharp line involves accuracy, precision, hardness, cold, oblong rights weakness, tenderness, light; curve - softness, tenderness, warmth, femininity, many curve excitement, strong emotion, strong movement; shrink down - laziness, fatigue; shrink up energy sustainability; wavy - elasticity, laziness, passivity, peace, gentleness and others.

\section{NATURE OF LINE}

The most characteristic feature of the line made in fine arts - graphic and from here the whole eligibility analysis of the line in the graph, combined with interior and exterior, because it is one of the middle, so that the most effective means of expression.

The line is actually visualized recording state of mind of the artist, his sensibility, character and aesthetics. Depending on the nature of the artist's feelings and visions line in its appearance varies from artist to artist. 


\section{ARTTIE $Y$}

Ipplied Resseirlches in Teechnics, Technologies and Eductition

Journal of the Faculty of Technics and Technologies, Trakia University https://sites.google.com/a/trakia-uni.bg/artte/

In one she is thin and soft, others hard and firm, with a third and a wide collar or heavy; some is sharp and cold, others warm, lyrical, dramatic. These features mean the very quality of the line.

Spontaneity the occurrence of line and allowing speaks more directly to the author than the subject matter that may be described. It follows that artistic expression is more important that the line is contained in itself than what it describes. For the look of the line have an important role and the means by which it is performed, tools and materials.

Same line displayed with different materials change their appearance (pencil, pen, brush). So every artist requires adequate material for its expression.

From the wide palette of lines that express different states of mind and qualities will mention some that are often found in the drawings: gentle, soft, warm, calm, lyrical, playful, hard, heavy, hard, rough, heavy, nervous, alert, tired cumbersome, vivid, dramatic, bold, masculine, monumental this is just the total content.

The same motive various artists will express any "their" line in each of them has a peculiar character. This is the road that takes place instantly understanding of the work of art before you understand thematic content.

Today has not attempted to consciousness that it depends on the sense of the direction and forms of what visually supports the head of the background colour to the type of materials that line is drawn.

Thus example the same line will also mean regardless of its same length and width, if withdrawn with shower, the other with a pencil.

\section{DESCRIPTION OF THE LINE GRAPHICS}

linocut technique known users of linocut Henry Matisse, Pablo Picasso. Original graphics by Alexander Jing made in technology linocut. Chief inspirational segment structure of nature with its virtues presented by the author's fingerprints.

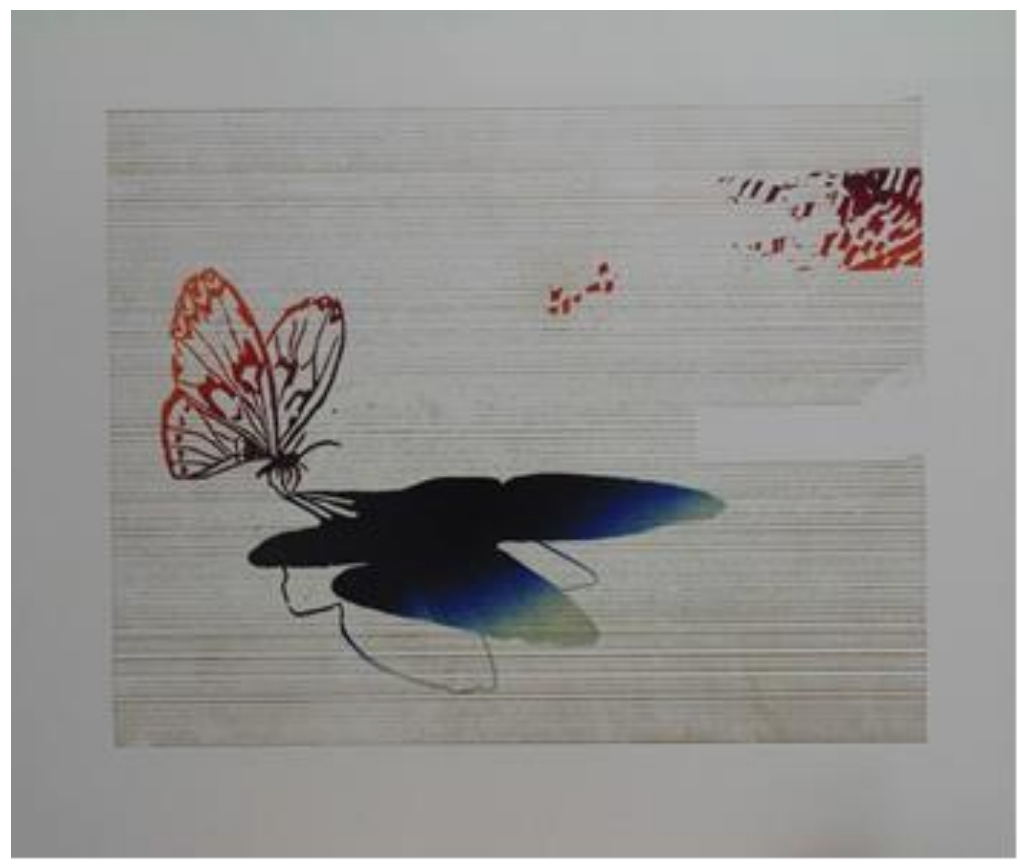

Figure 1. Line graphics 


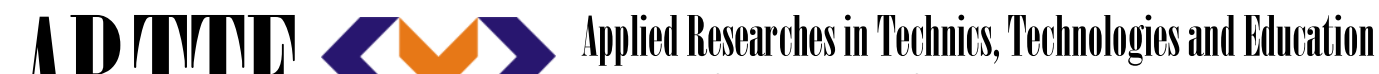 Journal of the Faculty of Technics and Technologies, Trakia University https://sites.google.com/a/trakia-uni.bg/artte/}

The line in the graphs is the most special place for expression that modelled a variety of ways inserted special expression. Choosing a topic that is processed in the engineering as the topic itself offers its transformation to the degree of realization of the idea, the concept art. Remind one approach used long schedule, access, which uses is in celebration of nature, to be displayed in graphic technique which carving in modern time changes with linocut the same effects (Figure 1).

Maximum simplification of line, colour, shape and colour and three-dimensional risk that the case be thrown out of range of criteria Fine viability, but with a strong attribute of the criteria used in the design viability.

Schematically display does that sort of yielding in cases qualify desire line to be illuminated and healthy and whole, graphical be released of unnecessary information per tonne explanation in order to escape the complexity of painting effects and treated topic to be within a simple content .

Line as an expression to be the main carrier in the simple construction of composition number and be faithful to the story-entered in each chart. The act in the treatment of colourtone is to say colour is used Valero. Nature is in flat surfaces space associative landscape or other abstract setting that closes the composition on the one hand as a justified case, on the other hand spread in imaginary space outside the frame (Figure 2).

The graphics are complemented by a colour that will function rendering artistic effect and the area and usually makes graphic ton.

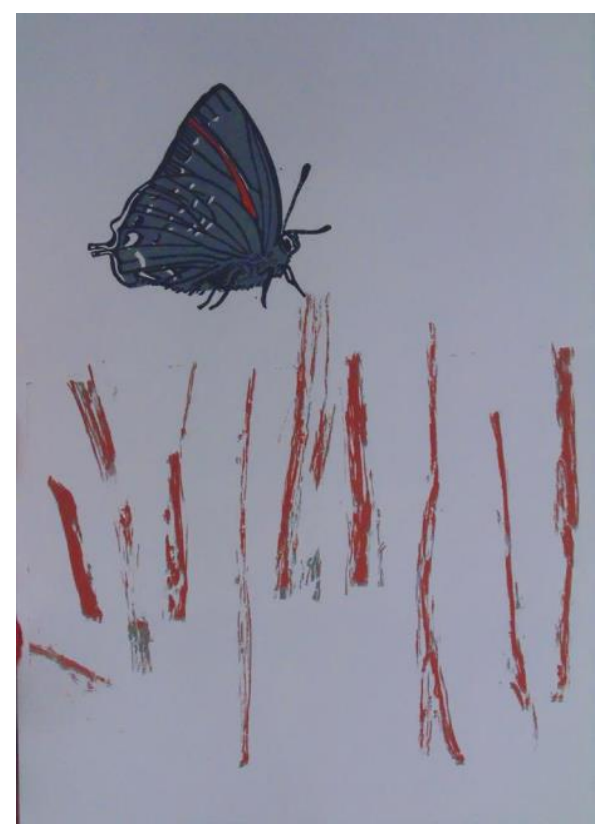

Figure 2. Print

\section{PRINT}

Art print has a long history, its beginning and for making books can be found in Egypt, where they used wooden boards for printing. Yet the earliest printed object originated in China in the 9th century BC, and already the 13th century this technique was brought to the Western world.

A printing is particularly widespread in the 16th century in Europe Albert works of Durer, Cranach Luke, and Hans Balding Green. Young, later artists have used their skills valuable reproductions of old photos, for propaganda purposes, social satire ITN.

IRITIE Vol. 5, No. 2, 2017 ISSN 1314-8788 (print), ISSN 1314-8796 (online), doi: 10.15547/artte.2017.02.011 
Even in the 20th century, printing was adopted as a technique, which is valuable in itself and as an artistic expression that has values by the effect of highlighting subtle prosthetics thread, soft texture of fine lines linocut.

Art print today is very similar to that of a few centuries ago. As with photomechanical reproduction can be grouped into three broad categories: relief, intaglio/offset and planography.

Chart as a visual technique opportunity for creative motion which extends into the interior and exterior

\subsection{The impact of the line of graphics as a composer as interior design}

Without colour - where you need to create and implement - in a decision called in only its dramatic to move the entire interior, the selected graph linocut if the basic technique with its concave and bruises closes entire floor. Of its outgoing lines are placed all functional forms in space. To meet the requirement should apply the same principles that apply to any good design and the only way to attract more attention and maintain interest.

Principle is to focus on the floor, highlighting which also has many examples. Here is very important to respect the hierarchy of importance of used items at the heart will be on the floor and that we have sent the message.

Graphics - linocut technique that can be implemented in the exterior.

\subsection{The impact of the line of graphics as a composer of form exterior design}

The impact of the line of graphics as a composer of form exterior design is placed on the floor, where the composition is seating - holiday and where start all moving lines.

The first of these principles in the creation of the idea is balance. The elements in shaping the space can be arranged to achieve harmony and balance that will allow the observer immediately notices and quick to react.

When this balance can be symmetrical, as in countless examples, but once established, it will be experimented in several versions. In its most typical form it already represents the quality of the material from which it is made, transforming them into an artistic expression.

\section{CONCLUSION}

The graph meets the requirements of interior and exterior.

Decisions are better when the selected subject on the chart merges with all requirements and criteria for the interior.

As the main recommendation we suggest trends always lead forward, provide the opportunities for shaping and space exploration, but putting such an approach in interior and exterior makes another dimension of space.

Storage and composed elements combined with the amount of space attach harmony, beauty of simplicity and avidity of space.

The essence of the furniture is in the structure, union, common function, but the end result is synthesis - aesthetic rationale and vision, not monotonous lightweight and celery. The most outrageous recognizable elements of modern design style of the interior and exterior of the line. The line is a brain start, definition, root from which further develops the fruit of the design itself.

The line is everywhere in design and all its details and elements of the main constructions maximum use in aesthetic purposes. 


\section{IRTTL}

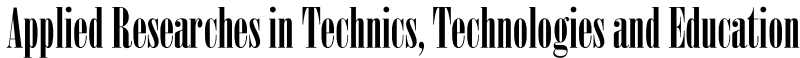

Journal of the Faculty of Technics and Technologies, Trakia University https://sites.google.com/a/trakia-uni.bg/artte/

\section{LITERATURE}

[1] Despot Katerina and Sandeva Vaska. (2013). Urban exterior graphical design in botanical garden. International Conference on Technics, Technologies and Education 2013.

[2] Dževad Hozo. Umjetnost multiorginala, Prva književna komuna Mostar, 1988.

[3] Ljubomir Gurinov, Graficen recnik v dizajna, Sofia, 2008.

[4] Rankov S., Dimcev V. Risuvane i izobrazitelno iskustvo, Sofia 1980.

[5] Sandeva Vaska and Despot Katerina. (2015). Composition of futurism in landscape architecture. 15th International Scientific Conference VSU 2015, 3 (3). pp. 23-28. ISSN 1314-071X.

[6] Sandeva Vaska and Despot Katerina. (2015). Design as mediator between the form and the reality of the user. 15th International Scientific Conference VSU 2015, 3 (3). pp. 915. ISSN 1314-071X.

[7] Zheleva-Martines Dobrina, Tektonikata kato teorija na formata i formoobrazuvaneto, Sofia, 2000. 